\title{
Retraction Note to: The efficacy of Guolin-Qigong on the body-mind health of Chinese women with breast cancer: a randomized controlled trial
}

Pei Liu ${ }^{1} \cdot$ Jieshu You ${ }^{1} \cdot$ Wing T. Y. Loo ${ }^{1} \cdot$ Youzhi Sun ${ }^{1,2} \cdot$ Yanhua He $^{1} \cdot$ Huiping Sit $^{3} \cdot$ Lei Jia $^{1} \cdot$ Meikuen Wong $^{1}$. Zhiyu Xia $^{4} \cdot$ Xiao Zheng $^{1} \cdot$ Zhiyu Wang $^{1} \cdot$ Neng Wang $^{1} \cdot$ Lixing Lao $^{1} \cdot$ Jianping Chen $^{1}$

Published online: 16 October 2020

(c) Springer Nature Switzerland AG 2020

\section{Retraction to: \\ Quality of Life Research (2017) 26:2321-2331 https://doi.org/10.1007/s11136-017-1576-7}

The authors have retracted this article [1]. Contrary to the statement in the article, the Institutional Review Board of the University of Hong Kong/Hospital Authority Hong Kong West Cluster issued a Notice of Termination of Approval on 16 June 2014 which carried the meaning of withdrawal of approval. All authors agree with this retraction.

\section{Reference}

1. Liu P, You J, Loo WTY, Sun Y, He Y, Sit H, Jia L, Wong M, Xia Z, Zheng X, Wang Z, Wang N, Lao L, Chen J (2017) The efficacy of Guolin-Qigong on the body-mind health of Chinese women with breast cancer: a randomized controlled trial. Qual Life Res 26:2321-2331. https://doi.org/10.1007/s11136-017-1576-7

Publisher's Note Springer Nature remains neutral with regard to jurisdictional claims in published maps and institutional affiliations.

The original article can be found online at https://doi.org/10.1007/ s11136-017-1576-7.

Jianping Chen

abchen@hku.hk

1 School of Chinese Medicine, The University of Hong Kong, 10 Sassoon Road, Pokfulam, Hong Kong

2 School of Basic Medicine, Jiangxi University of Traditional Chinese Medicine, Nanchang 330004, Jiangxi, People's Republic of China

3 Department of Sports Science and Physical Education, The Chinese University of Hong Kong, Pokfulam, Hong Kong

4 School of Public Health, Peking University, Beijing 100191, People's Republic of China 